\title{
A Survey on the Reactivity of Phenyliodonium Ylide of 2- Hydroxy-1,4-Naphthoquinone with Amino Compounds
}

\author{
Konstantina Spagou, Elizabeth Malamidou-Xenikaki and Spyros Spyroudis* \\ Laboratory of Organic Chemistry, Chemistry Department, University of Thessaloniki, Thessaloniki \\ 54124, Greece. Tel.: (+30) 2310-997833, Fax: (+30) 2310-997679
}

*Author to whom correspondence should be addressed; e-mail sspyr@chem.auth.gr

Received: 1 July 2004 / Accepted: 13 July 2004 / Published: 31 January 2005

\begin{abstract}
The phenyliodonium ylide of 2-hydroxy-1,4-naphthoquinone reacts with aminoesters, ureas, aminoalcohols and aminophenols in refluxing dichloromethane to afford good yields of indanedione 2-carboxamido compounds, that in solution exist in an enol-amide form. The same reactants in a copper-catalyzed reaction afford mainly the corresponding $\mathrm{N}$-arylo compounds. Arylhydrazines are mainly oxidized by the ylide and arylation occurs only in a low yield.
\end{abstract}

Keywords: Phenyliodonium ylides, 2-hydroxy-1,4-naphthoquinone, aminoesters, ureas.

\section{Introduction}

Quinones bearing hydroxy groups on the quinone ring represent an interesting class within the quinone family. A great variety of these hydroxyquinones are found in nature [1] and almost all of them exhibit some kind of biological activity. Synthesis and reaction patterns of hydroxyquinones have been reviewed [2].

One of the most interesting properties of hydroxyquinones is the easy formation of aryliodonium ylides upon reaction with bis(acetoxy)iodoarenes [2]. These ylides (better considered as 1,4zwitterionic compounds) are labile molecules which have found interesting applications in synthesis [3]. Recently we reported the reaction of aryliodonium ylides of 2-hydroxy-1,4-naphthoquinone (1) with amines [4]. In refluxing dichloromethane or under $\mathrm{Pd}(\mathrm{OAc})_{2}$ catalysis at room temperature a ring contraction occurs and indanedione amides, stabilized in an unusual enol-amide form 2, are isolated in good yields. In contrast the copper-catalyzed reaction affords arylated amines $\mathbf{3}$ and 
3-iodo-4-hydroxy-1,2-naphthoquinone (4), a rare example of an hydroxyquinone in $o$-tautomeric form (Scheme 1).

\section{Scheme 1}

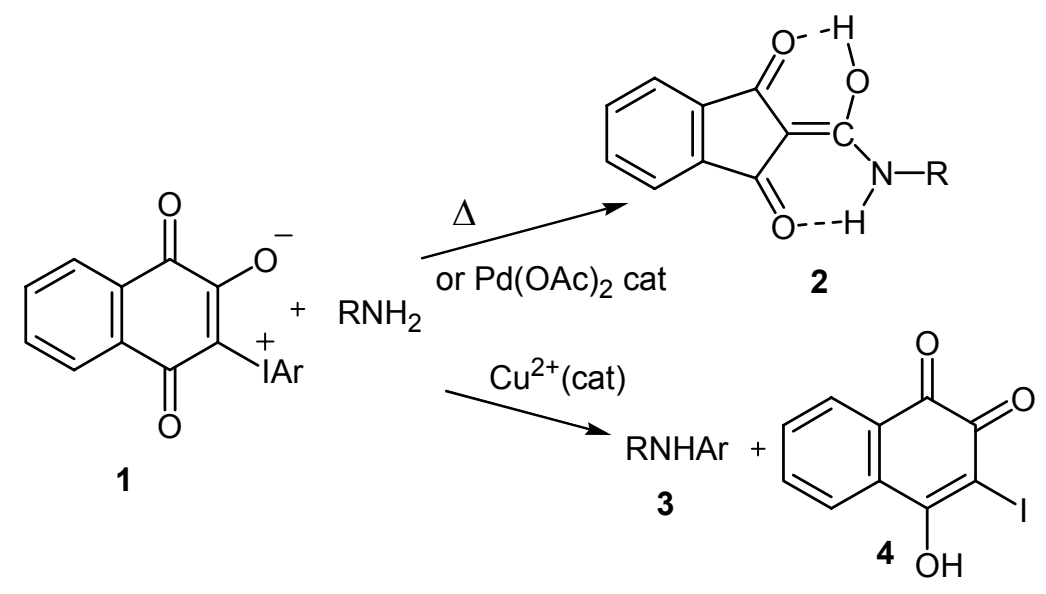

The thermal reaction proceeds through $\mathrm{C}_{\text {quin- }} \mathrm{I}$ bond fission, Wolff-rearrangement of the resulting carbene to the corresponding dioxo ketene and reaction of the latter with the amino group. As for the $\mathrm{Cu}^{2+}$-catalyzed reaction we proposed [4] a reaction pathway involving the complexation of copper with 2-hydroxy-1,4-naphthoquinone (lawsone), formation of an intermediate iodane in an $o$-quinonic form and degradation of the latter to arylated amine and iodoquinone 4 . These findings prompted us to extend our studies on the reactivity of ylide 1 with other classes of amino compounds and we wish to report our results here.

\section{Results and Discussion}

Both thermal and $\mathrm{Cu}^{2+}$-catalyzed reactions of $\mathbf{1}$ with different aminoesters were tried first, considering the importance of the aminoester moiety.

In refluxing $\mathrm{CH}_{2} \mathrm{Cl}_{2}$ equimolecular quantities of $\mathbf{1}$ and aromatic aminoesters, such as methyl anthranilinate (5a) and ethyl $p$-aminobenzoate (5b), afforded high yields of the corresponding carboxamide esters 6a,b (Scheme 2).

\section{Scheme 2}

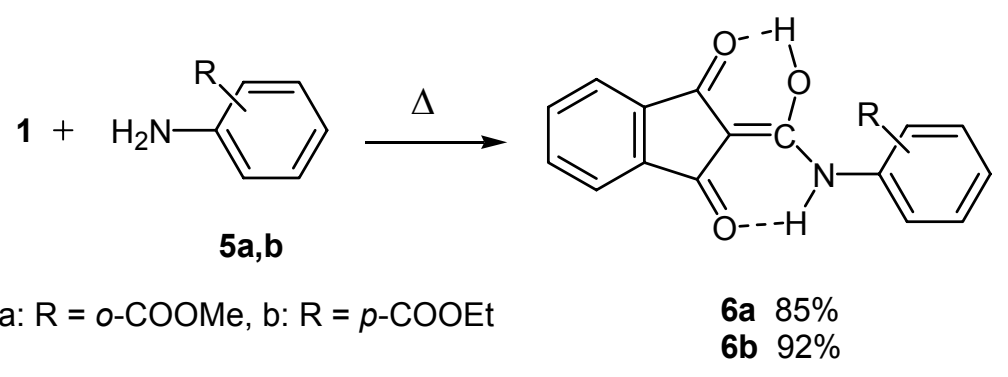


Carboxamides 6 were isolated by simple filtration and all spectroscopic evidence is consistent with the enol-amide form presented in the scheme, a form which is stabilized by the two hydrogen bonds.

In contrast the $\mathrm{Cu}^{2+}$-catalyzed reaction of ylide $\mathbf{1}$ with aminoesters $\mathbf{5}$ afforded, aside from the expected arylation products 7 and 3-iodo-4-hydroxy-1,2-naphthoquinone (4), the iodo ether 9 and the hydroxy amino-quinonic compounds $\mathbf{8}$. Ether $\mathbf{9}$ is the "normal" phenyl migration from iodine to oxygen product [4] and $\mathbf{8}$ is the result of direct attack of the amino group to carbon-3 of the quinonic ring with the simultaneous reductive elimination of iodobenzene (Scheme 3).

\section{Scheme 3}

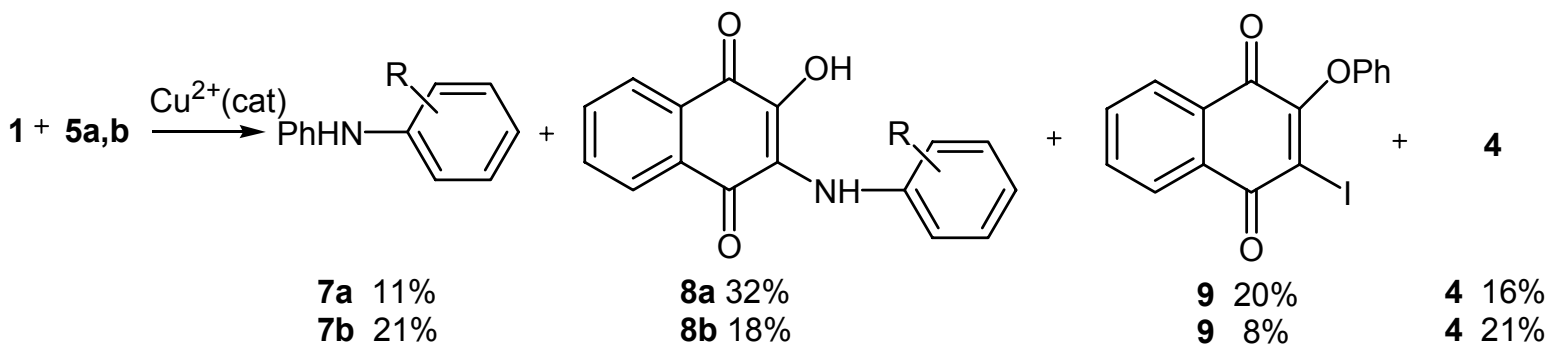

It must be noted that compounds of type $\mathbf{8}$ were not isolated from the reaction of $\mathbf{1}$ with amines and this difference in reactivity, as well as low yields of products 7 , in our case can be explained by the weaker nucleophilicity of the amino group. The lower yield of $\mathbf{7 a}$, compared to $\mathbf{7} \mathbf{b}$, could be attributed to steric hindrance of the former.

The reaction of 1 with ethyl glycinate (10) followed the same reaction pathway affording the enol-amide derivative 11, crystallized with one molecule of water (thermally) and the phenyl aminoester 12, as well as iodoquinone 4, (catalytically) (Scheme 4).

\section{Scheme 4}

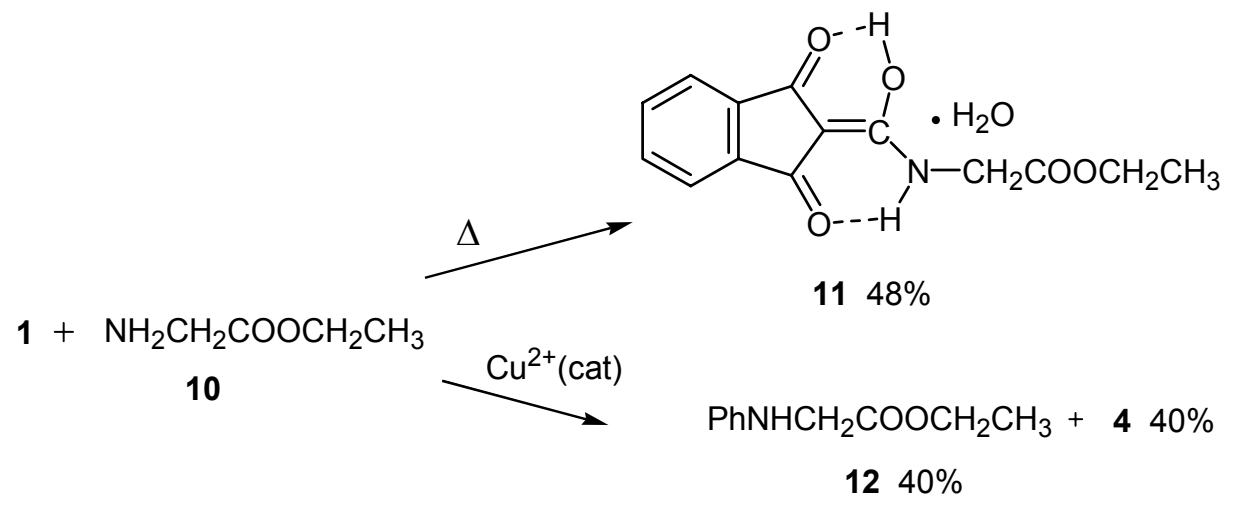

When the same reactions were repeated using the aminoacid 13, instead of its ester, the results were not satisfactory. Although spectroscopic evidence indicates the formation of $\mathbf{1 4}$ (Scheme 5), it is very difficult to separate it from the considerable amount of unreacted amino acid 13. This was achieved by repeated washings of the product with water but in this case hydrated $\mathbf{1 4}$ was obtained with simultaneous partial hydrolysis of the product. Moreover, the product exists in solution in 
equilibrium with some other enolic form(s), perhaps due to its treatment with water. Nevertheless, the ${ }^{1} \mathrm{H}-\mathrm{NMR}$ spectrum, characteristic ${ }^{13} \mathrm{C}-\mathrm{NMR}$ peaks (190.4 for $\mathrm{C}=\mathrm{O}$ of the cyclopentane ring, 171.3 for the enolic carbon, 168.7 for the $\mathrm{C}=\mathrm{O}$ of the acid, 97.5 for the ethylenic carbon of the ring) and a molecular peak at 247 all indicate the formation of $\mathbf{1 4 .}$

\section{Scheme 5}

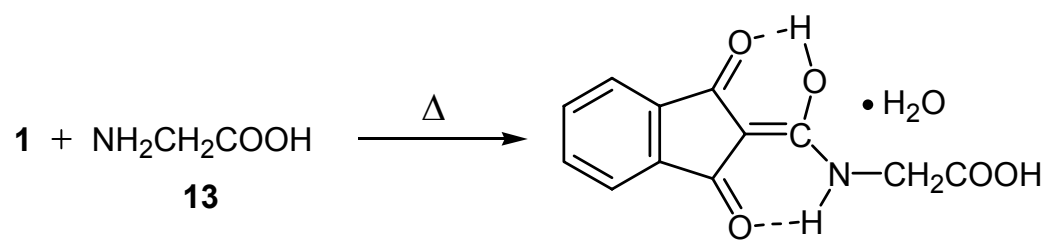

$1437 \%$

The corresponding $\mathrm{Cu}^{2+}$-catalyzed reaction did not proceed at all, probably due to the known [5] chelation of copper ions with aminoacids, which leaves no available copper for complexation with the hydroxyquinone moiety.

Finally the thermal reaction of 1 with the methyl 3-aminocrotonate (15) afforded the enol-amide 16 in low yield. The $\mathrm{Cu}^{2+}$-catalyzed reaction led to a complex mixture of products, difficult to separate and identify, although the isolation of iodoquinone 4 in 37\% yield indicates the transfer of phenyl group to the enamino ester, analogously to the above reported reactions (Scheme 6).

\section{Scheme 6}

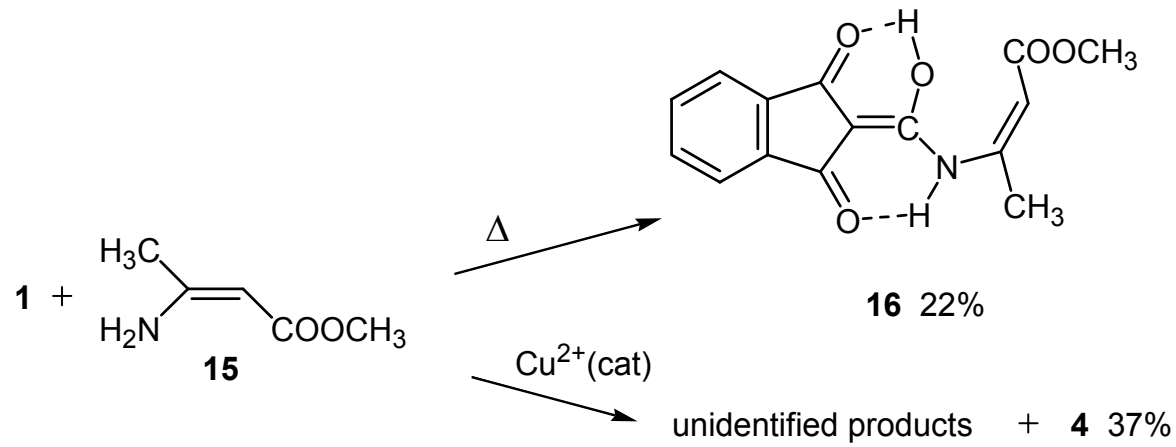

An interesting issue to address was the reactivity of the amino group in the presence of a hydroxy group in the molecule. For this reason the reactions of ylide $\mathbf{1}$ with an amino alcohol and an amino phenol were investigated.

Whereas the thermal reaction of 1 with 3-amino-propanol (17) afforded the expected enol-amide 18 (crystallized with one molecule of water) in a good yield, from the corresponding $\mathrm{Cu}^{2+}$-catalyzed reaction only 5\% of phenylamino-propanol 19 was isolated (Scheme 7). This low yield can again be attributed to a possible formation of a complex between 17 and copper ions.

It is also possible that the enol-amide $\mathbf{1 8}$ exists in solution (in $\mathrm{CDCl}_{3}-\mathrm{DMSO}-\mathrm{d}_{6}$ ) in equilibrium with other enolic forms (possibly with the participation of the free hydroxy group in hydrogen bonds) as indicated by the broad signals in the ${ }^{1} \mathrm{H}-\mathrm{NMR}$ spectrum and an excess of small peaks in 
the ${ }^{13} \mathrm{C}-\mathrm{NMR}$, although the characteristic stronger peaks for all these types of compounds at 189.1, 161.5 and $94.1 \mathrm{ppm}$ indicate that the proposed structure is the predominant one.

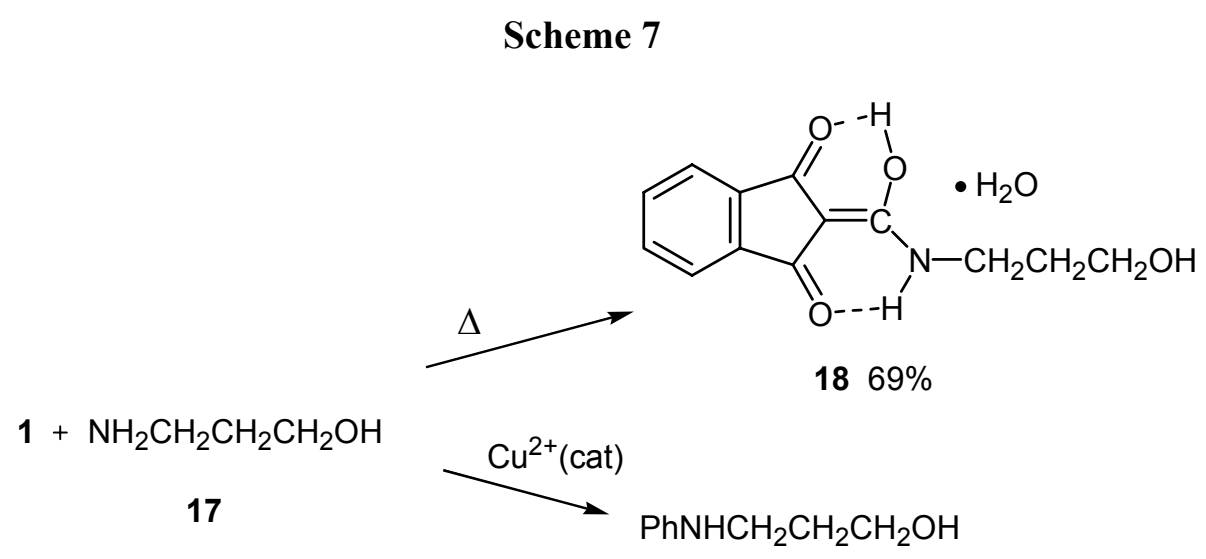

$195 \%$

In contrast both reactions of 1 with 3-aminophenol (20) worked reasonably well. The enol-amide 21 was isolated in a clean 93\% yield from the thermal reaction and 3-phenylaminophenol (23) was the main product, in an overall $71 \%$ yield, of the $\mathrm{Cu}^{2+}$-catalyzed reaction. It is interesting to note that a molecular complex 22 of 3-phenylamino-phenol (23) with iodine was eluted first from the column in $20 \%$ yield, followed by free $\mathbf{2 3}$ in $51 \%$ yield. Stable molecular complexes of iodine with electron rich aromatic rings is a well known class of compounds [6], although in our case the reaction pathway that produces molecular iodine is not at all clear. Finally the usual iodoquinone 4 was isolated in 55\% yield (Scheme 8).

\section{Scheme 8}

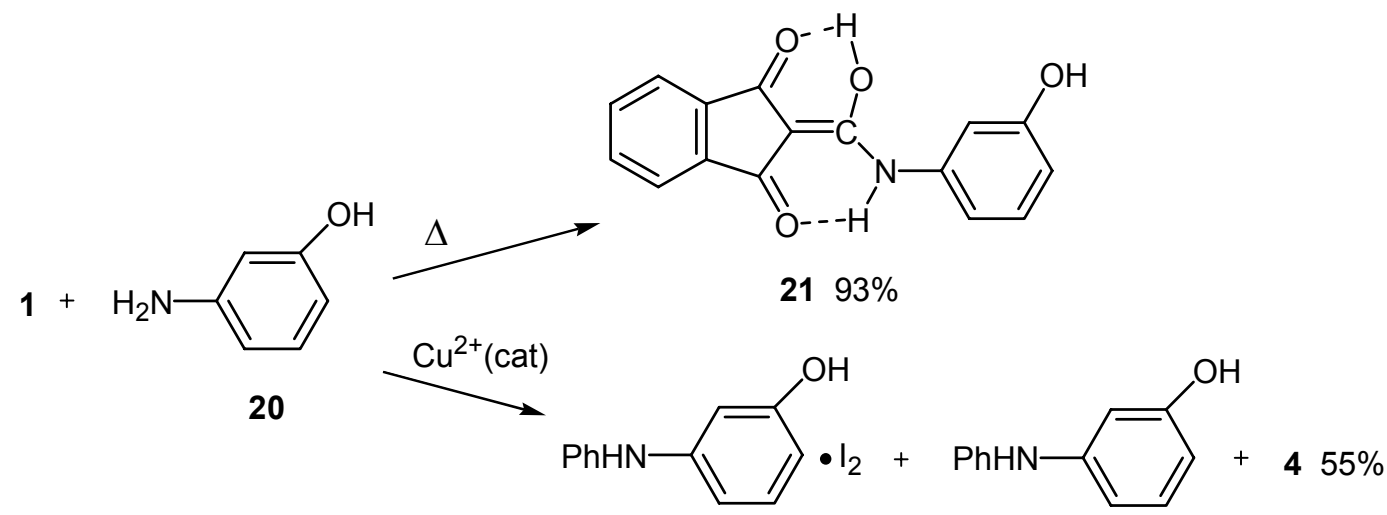

$2220 \%$

$2351 \%$

Urea (24) also reacts with the intermediate dioxo ketene to afford the enol-amide $\mathbf{2 5}$ in $80 \%$ yield (Scheme 9). The corresponding $\mathrm{Cu}^{2+}$-catalyzed reaction afforded a complex mixture of products impossible to separate. 


\section{Scheme 9}

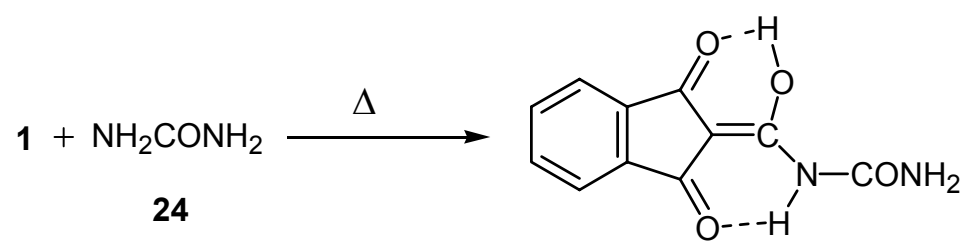

$2580 \%$

Finally, the reactivity of $\mathbf{1}$ towards the hydrazine group was investigated. In this case the oxidation of hydrazine by ylide $\mathbf{1}$ is the main reaction pathway. $p$-Tolylhydrazine (26) reacts violently with 1 , with vigorous gas evolution, undoubtedly $\mathrm{N}_{2}$, and the only isolable products were iodobenzene and lawsone (27). The same products, iodobenzene and lawsone, were also isolated from the copper-catalyzed reaction. In this case the isolation of small amounts (5-10\% yield) of 4methylazobenzene (28) indicates that arylation of $p$-tolylhydrazine occurs in a small extent and the resulting 1-phenyl-2-tolyl hydrazine is then oxidized to the corresponding azo compound $\mathbf{2 8}$.

\section{Scheme 10}

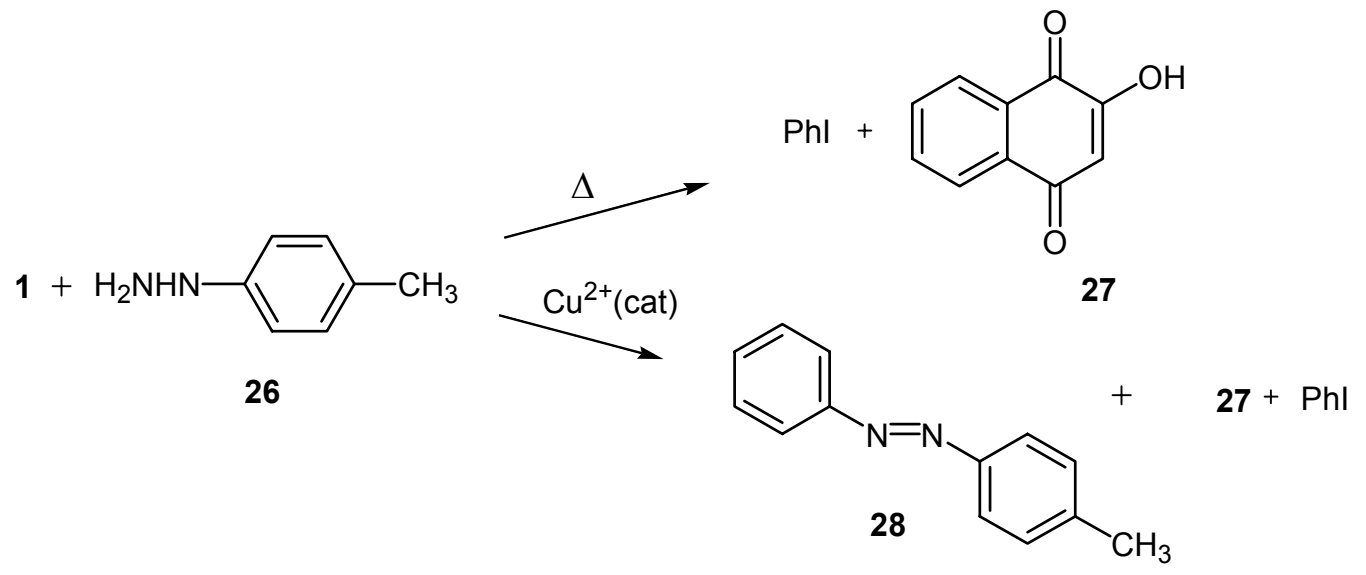

\section{Conclusions}

From the above survey two main conclusions can be drawn: first, various amino compounds react with the dioxo ketene produced by the thermal decomposition of ylide $\mathbf{1}$ to afford good to high yields of dioxo amides stabilized in their enolic form. Since the latter are easily isolable (by simple filtration) and preliminary experiments showed their convenient decomposition to the initial amino compounds, this reaction could be used for the protection of the amino group. This protectiondeprotection scheme will be the subject of our next research efforts.

Second, the $\mathrm{Cu}^{2+}$-catalyzed reaction leads to phenyl (or aryl if aryliodonium ylides are used) amino compounds but yields are generally not too high. Since some excellent methods for copperassisted arylation of amino compounds are reported ([5,7] just to mention a few of the latest), this reaction may find limited synthetic application. On the other hand this reaction is of mechanistic interest and more has to be done in order to better understand the catalytic role of copper. This study 
could lead to higher yields of arylation products or different products such as the amino quinones $\mathbf{8}$, isolated from the reaction of $\mathbf{1}$ with aromatic aminoesters.

\section{Experimental}

\section{General}

Melting points were determined on a Kofler hot stage apparatus and are uncorrected. ${ }^{1} \mathrm{H}-\mathrm{NMR}$ and ${ }^{13} \mathrm{C}$-NMR were run on a Bruker AM 300 spectrometer $\left({ }^{1} \mathrm{H}-\mathrm{NMR}\right.$ at $300 \mathrm{MHz}$ and ${ }^{13} \mathrm{C}-\mathrm{NMR}$ at $75 \mathrm{MHz}$, respectively) using TMS as internal standard. Mass spectra were recorded on a VG-TS 250 spectrometer at $70 \mathrm{eV}$. Elemental analyses were performed using a Perkin-Elmer 2400-II analyzer. Column chromatography was carried out on Merck silica gel 60 (30-270 mesh). Ylide 1 was prepared from lawsone and (diacetoxy)iodobenzene [3a].

General procedure for the thermal reaction of $\mathbf{1}$ with amino compounds.

Ylide 1 (1 mmol) and the appropriate amino compound $(1 \mathrm{mmol})$ were suspended in $\mathrm{CH}_{2} \mathrm{Cl}_{2}(16$ $\mathrm{mL}$ ) and the suspension was refluxed for 4-5 hours until complete decomposition of $\mathbf{1}$ (either a clear solution resulted or a change in the colour of the solid from orange to yellow, depending on the solubility of the product). Any solid was filtered, the filtrate (or the initial clear solution) was concentrated to one third of its volume and the resulting solid was combined with the first solid and washed repeatedly with small portions of $\mathrm{CH}_{2} \mathrm{Cl}_{2}$.

General procedure for the copper-catalyzed reaction of $\mathbf{1}$ with amino compounds.

Ylide 1 (1 mmol), the appropriate amino compound $(1 \mathrm{mmol})$ and $\mathrm{Cu}\left(\mathrm{CF}_{3} \mathrm{SO}_{3}\right)_{2}(20 \mathrm{mg}, 5 \mathrm{~mole}$ \%) were suspended in $\mathrm{CH}_{2} \mathrm{Cl}_{2}(16 \mathrm{~mL})$ and the suspension was stirred at room temperature for 2-3 days till the complete disappearance of $\mathbf{1}$. Small quantities of solids were filtered off, the resulting solution was concentrated and chromatographed on a column (silica gel, gradient of hexanes-ethyl acetate gradually increasing from 4:1). The first fraction was always a small amount of iodobenzene. Pure ethyl acetate with a few drops of methanol were necessary in order to elute the red iodoquinone 4.

Reaction with methyl 2-aminobenzoate (5a) and ethyl 4-aminobenzoate (5b)

Thermal reaction. From the reaction with 5a methyl 2-\{[(1,3-dioxo-1,3-dihydro-2H-inden-2ylidene)-(hydroxy)methyl] amino benzoate (6a) was isolated in $85 \%$ yield, mp $156-159{ }^{\circ} \mathrm{C}$; ${ }^{1} \mathrm{H}-\mathrm{NMR}$ $\left(\mathrm{CDCl}_{3}\right): \delta 12.00(\mathrm{~s}, 1 \mathrm{H}), 8.46(\mathrm{~d}, \mathrm{~J}=8.6 \mathrm{~Hz}, 1 \mathrm{H}), 8.12(\mathrm{~d}, \mathrm{~J}=7.9 \mathrm{~Hz}, 1 \mathrm{H}), 7.74-7.67(\mathrm{~m}, 1 \mathrm{H})$, 7.67$7.54(\mathrm{~m}, 5 \mathrm{H}), 7.21(\mathrm{t}, \mathrm{J}=7.6 \mathrm{~Hz}, 1 \mathrm{H}), 4.12(\mathrm{~s}, 3 \mathrm{H}) ;{ }^{13} \mathrm{C}-\mathrm{NMR}\left(\mathrm{CDCl}_{3}\right): \delta 192.4,189.4,167.4,165.9$, 138.7, 137.1, 136.5, 134.0, 133.7, 132.0, 131.5, 124.1, 122.3, 121.4, 117.9, 98.1, 52.8; MS m/z: 323 $\left(\mathrm{M}^{+}, 18\right), 172$ (10), 151 (100), 119 (87); Anal. Calcd for $\mathrm{C}_{18} \mathrm{H}_{13} \mathrm{NO}_{5}$ : C, 66.87; H, 4.05; N, 4.33. Found: C, 66.43; H, 4.11; N, 4.17. 
From the reaction with $\mathbf{5 b}$ ethyl 4-\{[(1,3-dioxo-1,3-dihydro-2H-inden-2-ylidene)(hydroxy)methyl]amino benzoate $(\mathbf{6 b})$ was isolated in $92 \%$ yield. $\mathrm{Mp} 151-154{ }^{\circ} \mathrm{C} ;{ }^{1} \mathrm{H}-\mathrm{NMR}\left(\mathrm{CDCl}_{3}\right): \delta 9.57$ (brs, 1H), 8.07 (d, J=8.5 Hz, 2H), 7.70-7.52 (m, 7H), 4.38 (q, J=7.0 Hz, 2H), 1.41 (t, J=7.0 Hz, 3H); ${ }^{13} \mathrm{C}-\mathrm{NMR}\left(\mathrm{CDCl}_{3}\right): \delta 191.6,190.5,165.9,140.2,137.0,133.7,133.4,131.0,127.0,122.4,121.7$, 119.9, 97.6, 61.1, 14.4; MS m/z: $337\left(\mathrm{M}^{+}, 15\right)$; Anal. Calcd for $\mathrm{C}_{19} \mathrm{H}_{15} \mathrm{NO}_{5}$ : C, 67.65; H, 4.48; N, 4.15. Found: C, 67.45; H, 4.34; N, 3.88.

Copper-catalyzed reaction. From the reaction with 5a the following compounds were isolated (in order of elution): 2-phenoxy-3-iodo-1,4-naphthoquinone (9) [4] in 20\% yield, methyl 2-phenylaminobenzoate (7a) in $11 \%$ yield, $\mathrm{mp} 57-58{ }^{\circ} \mathrm{C}$, lit. [8] mp 58-59 ${ }^{\circ} \mathrm{C} ;{ }^{1} \mathrm{H}-\mathrm{NMR}\left(\mathrm{CDCl}_{3}\right): \delta 9.46(\mathrm{~s}$, 1H), $7.96(\mathrm{~d}, \mathrm{~J}=8.5 \mathrm{~Hz}, 1 \mathrm{H}), 7.38-7.23(\mathrm{~m}, 6 \mathrm{H}), 7.09$ (t, J=7.5 Hz, 1H), $6.73(\mathrm{t}, \mathrm{J}=7.5 \mathrm{~Hz}, 1 \mathrm{H}), 3.90$ (s, 3H); MS m/z: 227 (M+100), 196 (87), 167 (95); methyl 2-[(3-hydroxy-1,4-dioxo-1,4-dihydro-2naphthalenyl)-amino]benzoate (8a) in $32 \%$ yield, mp $149-152{ }^{\circ} \mathrm{C} ;{ }^{1} \mathrm{H}-\mathrm{NMR}\left(\mathrm{CDCl}_{3}\right): \delta 9.88(\mathrm{~s}, 1 \mathrm{H})$, 8.14-8.02 (m, 2H), 7.96 (d, J=7.9 Hz, 1H), 7.73-7.63 (m, 2H), 7.44 (t, J=7.0 Hz, 1H), 7.33 (brs, 1H), $6.95(\mathrm{t}, \mathrm{J}=7.3 \mathrm{~Hz}, 1 \mathrm{H}), 6.76(\mathrm{~d}, \mathrm{~J}=8.6 \mathrm{~Hz}, 1 \mathrm{H}), 3.94(\mathrm{~s}, 3 \mathrm{H}) ;{ }^{13} \mathrm{C}-\mathrm{NMR}\left(\mathrm{CDCl}_{3}\right): \delta 182.0,180.1$, $168.4,141.9,138.8,134.0,133.8,132.8,131.3,130.8,130.1,126.9,126.1,123.5,120.3,120.2$, 116.0, 52.2; MS m/z: $323\left(\mathrm{M}^{+}, 47\right), 263$ (70), 151 (88), 119 (100); Anal. Calcd for $\mathrm{C}_{18} \mathrm{H}_{13} \mathrm{NO}_{5}$ : C, 66.87; H, 4.05; N, 4.33. Found: C, 66.51; H, 4.22; N, 4.42 and finally, 3-iodo-4-hydroxy-1,2naphthoquinone (4) [4] in $16 \%$ yield.

From the reaction with $\mathbf{5 b}$ the following compounds were isolated (in order of elution): 9 [4] in $8 \%$ yield, ethyl 4-phenylaminobenzoate (7b) in $21 \%$ yield, mp $95-98{ }^{\circ} \mathrm{C} ;{ }^{1} \mathrm{H}-\mathrm{NMR}\left(\mathrm{CDCl}_{3}\right): \delta 7.92$ $(\mathrm{d}, \mathrm{J}=8.9 \mathrm{~Hz}, 2 \mathrm{H}), 7.32(\mathrm{t}, \mathrm{J}=7.9 \mathrm{~Hz}, 2 \mathrm{H}), 7.16(\mathrm{~d}, \mathrm{~J}=7.3 \mathrm{~Hz}, 2 \mathrm{H}), 7.05(\mathrm{t}, \mathrm{J}=7.3 \mathrm{~Hz}, 1 \mathrm{H}), 6.98(\mathrm{~d}, \mathrm{~J}$ $=8.9 \mathrm{~Hz}, 2 \mathrm{H}), 6.11$ (brs, $1 \mathrm{H}), 4.33(\mathrm{q}, \mathrm{J}=7.0 \mathrm{~Hz}, 2 \mathrm{H}), 1.37(\mathrm{t}, \mathrm{J}=7.0 \mathrm{~Hz}, 3 \mathrm{H}) ;{ }^{13} \mathrm{C}-\mathrm{NMR}\left(\mathrm{CDCl}_{3}\right): \delta$ 166.6, 148.0, 141.0, 131.4, 129.5, 127.7, 123.0, 120.3, 114.6, 60.5, 14.4; MS m/z: $241\left(\mathrm{M}^{+}, 100\right)$, 213 (48), 196 (66), 167 (66); Anal. Calcd for $\mathrm{C}_{15} \mathrm{H}_{15} \mathrm{NO}_{2}$ : C, 74.67; H, 6.27; N, 5.81. Found: C, 74.35; H, 6.16; N, 5.80; ethyl 4-[(3-hydroxy-1,4-dioxo-1,4-dihydro-2-naphthalenyl)-amino]benzoate (8b) in 18\% yield, mp 223-226 ${ }^{\circ} \mathrm{C} ;{ }^{1} \mathrm{H}-\mathrm{NMR}$ ( $\mathrm{CDCl}_{3} / \mathrm{DMSO}^{\left.-\mathrm{d}_{6}\right): \delta} 9.11$ (br, $\left.1 \mathrm{H}\right), 8.11-8.03(\mathrm{~m}, 2 \mathrm{H})$, $7.93(\mathrm{~d}, \mathrm{~J}=8.5 \mathrm{~Hz}, 2 \mathrm{H}), 7.74-7.66$ (m, 2H), 7.22 (brs, 1H), 6.92 (d, J=8.5 Hz, 2H), 4.34 (q, J=7.3 Hz, $2 \mathrm{H}), 1.38(\mathrm{t}, \mathrm{J}=7.3 \mathrm{~Hz}, 3 \mathrm{H}) ;{ }^{13} \mathrm{C}-\mathrm{NMR}\left(\mathrm{CDCl}_{3} / \mathrm{DMSO}_{-} \mathrm{d}_{6}\right): \delta 181.1,179.0,165.3,144.4,141.4$, 132.6, 130.1, 129.6, 128.8, 125.2, 124.9, 123.3, 121.1, 117.4, 59.3, 13.4; MS m/z: $337\left(\mathrm{M}^{+}, 100\right)$, 309 (18), 292 (25), 264 (30), 120 (33), 104 (38); Anal. Calcd for $\mathrm{C}_{19} \mathrm{H}_{15} \mathrm{NO}_{5}$ : C, 67.65; H, 4.48; N, 4.15. Found: C, 67.39; H, 4.29; N, 4.03, and finally, compound 4 [4] in 21\% yield.

\section{Reaction with ethyl glycinate (10)}

Thermal reaction. From the reaction with 10 ethyl 2-\{[(1,3-dioxo-1,3-dihydro-2H-inden-2ylidene)(hydroxy)methyl] amino facetate (11) was isolated in $48 \%$ yield, mp $124-126{ }^{\circ} \mathrm{C}$; ${ }^{1} \mathrm{H}-\mathrm{NMR}$ $\left(\mathrm{CDCl}_{3} / \mathrm{DMSO}_{-} \mathrm{d}_{6}\right): \delta 8.59$ (brs, $\left.1 \mathrm{H}\right), 7.67-7.50(\mathrm{~m}, 4 \mathrm{H}), 6.11$ (br, 1-3H, $\left.\mathrm{H}_{2} \mathrm{O}\right), 4.22$ (q, J=6.7 Hz, 2H), 4.19 (s, 2H), 1.30 (t, J=6.7 Hz, 3H); ${ }^{13} \mathrm{C}-\mathrm{NMR}\left(\mathrm{CDCl}_{3} / \mathrm{DMSO}_{6}\right)$ : $\delta 189.8,167.5,165.5,136.5$, 131.6, 119.8, 94.0, 60.1, 39.8, 12.9; MS m/z: $276\left(\mathrm{M}^{+}+1,87\right), 275\left(\mathrm{M}^{+}, 77\right), 229$ (26), 202 (32), 173 (100), 104 (56), 89 (65); Anal. Calcd for $\mathrm{C}_{14} \mathrm{H}_{13} \mathrm{NO}_{5} \cdot \mathrm{H}_{2} \mathrm{O}$ : C, 57.34; H, 5.15; N, 4.78. Found: C, $57.09 ; \mathrm{H}, 4.91 ; \mathrm{N}, 4.95$. 
Copper-catalyzed reaction. From the reaction with $\mathbf{1 0}$ the following compounds were isolated (in order of elution): Ethyl $N$-phenylglycinate (12) [9] in $40 \%$ yield, oil; ${ }^{1} \mathrm{H}-\mathrm{NMR}\left(\mathrm{CDCl}_{3}\right): \delta, 7.19(\mathrm{t}, \mathrm{J}$ $=7.7 \mathrm{~Hz}, 2 \mathrm{H}), 6.74(\mathrm{t}, \mathrm{J}=7.7 \mathrm{~Hz}, 1 \mathrm{H}), 6.61(\mathrm{~d}, \mathrm{~J}=8.3 \mathrm{~Hz}, 2 \mathrm{H}), 4.24$ (q, J=7.0 Hz, 2H), 4.26 (brs, $1 \mathrm{H}$, overlapping), $3.89(\mathrm{~s}, 2 \mathrm{H}), 1.29(\mathrm{t}, \mathrm{J}=7.0 \mathrm{~Hz}, 3 \mathrm{H}) ;{ }^{13} \mathrm{C}-\mathrm{NMR}\left(\mathrm{CDCl}_{3}\right): \delta 171.1,147.0,129.3,118.2$, $113.0,61.3,45.9,14.2$ and compound 4 [4] in $40 \%$ yield.

Reaction with glycine (13)

Thermal reaction. Ylide 1 (1 mmol) and glycine $(\mathbf{1 3}, 1 \mathrm{mmol})$ in $\mathrm{CH}_{2} \mathrm{Cl}_{2}(16 \mathrm{~mL})$ was refluxed for 10h. The resulting solid $(150 \mathrm{mg})$ was filtered and washed twice with small amounts of water to afford 2-\{[(1,3-dioxo-1,3-dihydro-2H-inden-2-ylidene)(hydroxy)methyl]amino\}acetic acid (14) in $37 \%$ yield, mp $188-191{ }^{\circ} \mathrm{C} ;{ }^{1} \mathrm{H}-\mathrm{NMR}\left(\mathrm{CDCl}_{3} / \mathrm{DMSO}_{6}\right)$ ) $\delta 8.83$ (brs, $\left.1 \mathrm{H}\right), 8.49$ (brs, $\left.1 \mathrm{H}\right), 7.90-7.63$ $(\mathrm{m}, 2 \mathrm{H}), 7.32-7.58(\mathrm{~m}, 3 \mathrm{H}), 3.99(\mathrm{~s}, 2 \mathrm{H}) ;{ }^{13} \mathrm{C}-\mathrm{NMR}\left(\mathrm{CDCl}_{3} / \mathrm{DMSO}_{6}\right)$, selected peaks: $\delta$ 190.4, 171.3, 168.7, 97.5, 39.9; MS m/z: $247\left(\mathrm{M}^{+}, 35\right), 173$ (60), 146 (75); Anal. Calcd for $\mathrm{C}_{12} \mathrm{H}_{9} \mathrm{NO}_{5} \cdot \mathrm{H}_{2} \mathrm{O}$ : C, 54.34; H, 4.18; N, 5.28. Found: C, 54.77; H, 3.95; N, 5.55 .

\section{Reaction with methyl 3-aminocrotonate (15)}

Thermal reaction. From the reaction with 15 methyl (Z)- 3-\{[(1,3-dioxo-1,3-dihydro-2H-inden-2ylidene)(hydroxy) methyl] amino\}-2-butenoate (16) was isolated in $22 \%$ yield, mp $148-151{ }^{\circ} \mathrm{C}$; ${ }^{1} \mathrm{H}$ NMR (CDCl $\left.{ }_{3} / \mathrm{DMSO}_{-} \mathrm{d}_{6}\right): \delta 12.07(\mathrm{~s}, 1 \mathrm{H}), 7.46-7.37(\mathrm{~m}, 5 \mathrm{H}), 4.68(\mathrm{~s}, 1 \mathrm{H}), 3.64(\mathrm{~s}, 3 \mathrm{H}), 2.41(\mathrm{~s}$, $3 \mathrm{H}) ;{ }^{13} \mathrm{C}-\mathrm{NMR}\left(\mathrm{CDCl}_{3} / \mathrm{DMSO}_{\mathrm{d}}\right): \delta$ 189.6, 166.1, 154.6, 138.5, 130.1, 118.3, 99.0, 92.3, 49.3, 23.0; MS m/z: 287 (M+, 7), 255 (8), 189 (30), 172 (73), 115 (88), 84 (100). No satisfactory elemental analysis could be obtained.

Copper-catalyzed reaction. The copper-catalyzed reaction gave a complicate mixture of products. The only isolable product was iodoquinone 4 in $37 \%$ yield.

\section{Reaction with 3-aminopropanol (17)}

Thermal reaction. From the reaction with 17 ethyl 2-\{hydroxy[(3-hydroxypropyl)amino]-methylene\}1H-indene-1,3(2H)-dione (18) was isolated in 69\% yield, mp 131-134 ${ }^{\circ} \mathrm{C} ;{ }^{1} \mathrm{H}-\mathrm{NMR}\left(\mathrm{CDCl}_{3} / \mathrm{DMSO}\right.$ $\left.\mathrm{d}_{6}\right): \delta 8.46$ (brs, $\left.1 \mathrm{H}\right), 8.07(\mathrm{br}, 1 \mathrm{H}), 7.49-7.30(\mathrm{~m}, 4 \mathrm{H}), 4.17(\mathrm{br}, 1 \mathrm{H}), 3.82-3.30(\mathrm{~m}, 2 \mathrm{H}$, overlapping with DMSO), 3.18-2.92 (m, 2H) 2.12-1.76 (m, 2H); MS m/z: $247\left(\mathrm{M}^{+}, 16\right), 173$ (35), 146 (20), 74 (100); Anal. Calcd for $\mathrm{C}_{13} \mathrm{H}_{13} \mathrm{NO}_{4} \cdot \mathrm{H}_{2} \mathrm{O}: \mathrm{C}, 58.86 ; \mathrm{H}, 5.70 ; \mathrm{N}, 5.28$. Found: C, 59.01; H, 5.52; N, 5.46 .

Copper-catalyzed reaction. The only isolable product was 3-phenylamino-propanol (19) [10] in 5\% yield, oil.; ${ }^{1} \mathrm{H}-\mathrm{NMR}\left(\mathrm{CDCl}_{3}\right): \delta, 7.19(\mathrm{t}, \mathrm{J}=7.9 \mathrm{~Hz}, 2 \mathrm{H}), 6.73(\mathrm{t}, \mathrm{J}=7.5 \mathrm{~Hz}, 1 \mathrm{H}), 6.66(\mathrm{~d}, \mathrm{~J}=7.9 \mathrm{~Hz}$, $2 \mathrm{H}), 3.83(\mathrm{t}, \mathrm{J}=6.0 \mathrm{~Hz}, 2 \mathrm{H}), 3.42-3.20(\mathrm{~m}, 2 \mathrm{H}), 2.34$ (brs, 2H), 2.00-1.83 (m, 2H); MS m/z: $151\left(\mathrm{M}^{+}\right.$, 20), 106 (100), 93 (17), 77 (30). 
Reaction with 3-aminophenol (20)

Thermal reaction. From the reaction with 20 2-[hydroxy(3-hydroxyanilino)methylene]-1H-indene1,3(2H)-dione (21) was isolated in $93 \%$ yield, mp 213-215 ${ }^{\circ} \mathrm{C} ;{ }^{1} \mathrm{H}-\mathrm{NMR}\left(\mathrm{CDCl}_{3} / \mathrm{DMSO}_{6}\right): \delta 10.20$ (brs, 1H), 8.45-7.75 (m, 6H), $7.43(\mathrm{t}, \mathrm{J}=8.2 \mathrm{~Hz}, 1 \mathrm{H}), 7.38(\mathrm{~s}, 1 \mathrm{H}), 7.23(\mathrm{~d}, \mathrm{~J}=7.9 \mathrm{~Hz}, 1 \mathrm{H}), 6.88(\mathrm{~d}, \mathrm{~J}=$ $7.3 \mathrm{~Hz}, 1 \mathrm{H}) ;{ }^{13} \mathrm{C}-\mathrm{NMR}\left(\mathrm{CDCl}_{3} / \mathrm{DMSO}_{-} \mathrm{d}_{6}\right): \delta 188.2,161.9,156.1,135.5,135.1,131.3,127.8,119.3$, 110.2, 109.8, 106.3, 94.9; MS m/z: $281\left(\mathrm{M}^{+}, 14\right), 172$ (27), 109 (100); Anal. Calcd for $\mathrm{C}_{16} \mathrm{H}_{11} \mathrm{NO}_{4}$ : C, 68.32; H, 3.94; N, 4.98. Found: C, 68.27; H, 3.90; N, 4.73.

Copper-catalyzed reaction. From the reaction with $\mathbf{2 0}$ the following compounds were isolated (in order of elution): 3-Phenylaminophenol $\cdot \mathrm{I}_{2}$ (22) in $20 \%$ yield, mp $69-73{ }^{\circ} \mathrm{C} ;{ }^{1} \mathrm{H}-\mathrm{NMR}\left(\mathrm{CDCl}_{3}\right): \delta$, 7.55 (d, J=8.4 Hz, 1H), 7.37-7.23 (m, 2H), 7.18-7.05 (m, 3H), 6.98 (t, J=6.8 Hz, 1H), $6.72(\mathrm{~s}, 1 \mathrm{H})$, $6.41(\mathrm{~d}, \mathrm{~J}=8.4 \mathrm{~Hz}, 1 \mathrm{H}), 5.70$ (brs, $1 \mathrm{H}), 5.20$ (brs, $1 \mathrm{H}) ;{ }^{13} \mathrm{C}-\mathrm{NMR}\left(\mathrm{CDCl}_{3}\right): \delta 155.6,146.0,141.9$, 138.3, 129.5, 122.3, 118.9, 111.8, 103.1; MS m/z 312 (M+I, 5), $311\left(\mathrm{M}^{+}+\mathrm{I}, 14\right), 254$ (19), $185\left(\mathrm{M}^{+}\right.$, 74), 154 (40), 127 (57), (due to loss of $\mathrm{I}_{2}$ no satisfactory elemental analysis could be obtained), 3phenylaminophenol (23) in 51\% yield, mp 79-82 ${ }^{\circ} \mathrm{C}$; ${ }^{1} \mathrm{H}-\mathrm{NMR}\left(\mathrm{CDCl}_{3}\right): \delta, 7.27(\mathrm{t}, \mathrm{J}=7.0 \mathrm{~Hz}, 2 \mathrm{H})$, 7.18-7.05 (m, 3H), 6.95 (t, J=6.7 Hz, 1H), 6.67-6.55 (m, 2H), 6.37 (d, J=7.9 Hz, 1H), 5.69 (brs, 1H), 4.72 (brs, $1 \mathrm{H}) ;{ }^{13} \mathrm{C}-\mathrm{NMR}\left(\mathrm{CDCl}_{3}\right): \delta 156.6,154.0,142.6,130.4,129.4,121.6,118.8,110.1,107.7$, 104.0; MS m/z: $185\left(\mathrm{M}^{+}, 100\right), 156(7), 77(13)$, in all respects identical to a commercially available sample, and compound 4 [4] in 55\% yield.

\section{Reaction with urea (24)}

Thermal reaction. From the reaction with urea $\mathrm{N}$-[(1,3-dioxo-1,3-dihydro-2H-inden-2ylidene)(hydroxy)-methyl]urea (25) was isolated in $80 \%$ yield, mp $214-217{ }^{\circ} \mathrm{C}$; ${ }^{1} \mathrm{H}-\mathrm{NMR}\left(\mathrm{CDCl}_{3} /\right.$ DMSO-d $\left.{ }_{6}\right): \delta 10.45(\mathrm{~s}, 1 \mathrm{H}), 7.60-7.42(\mathrm{~m}, 4 \mathrm{H}), 7.42-7.18(\mathrm{br}, 3 \mathrm{H}) ;{ }^{13} \mathrm{C}-\mathrm{NMR}\left(\mathrm{CDCl}_{3} / \mathrm{DMSO}-\mathrm{d}_{6}\right): \delta$ 188.8, 163.1, 154.2, 137.1, 130.4, 118.5, 96.6; MS m/z $232\left(\mathrm{M}^{+}, 12\right), 189$ (100), 172 (84), 104 (88); Anal. Calcd for $\mathrm{C}_{11} \mathrm{H}_{8} \mathrm{~N}_{2} \mathrm{O}_{4}$ : C, 56.90; H, 3.47; N, 12.06. Found: C, 56.53; H, 3.61; N, 12.41 .

\section{Reaction with p-tolylhydrazine (26)}

Free $p$-tolylhydrazine was isolated from its hydrochloric salt with aqueous $\mathrm{NaOH}$ treatment and extraction with $\mathrm{CH}_{2} \mathrm{Cl}_{2}$.

Thermal reaction. The reaction of $\mathbf{2 6}$ with ylide $\mathbf{1}$ in refluxing $\mathrm{CH}_{2} \mathrm{Cl}_{2}$ was completed in 5 minutes with vigorous gas evolution. The only isolable products were iodobenzene and lawsone (27) in varying high yields.

Copper-catalyzed reaction. The isolable products was 4-methyl-azobenzene (28) (in 7\% yield), mp 70-71 ${ }^{\circ} \mathrm{C}$, lit. [11] mp $72{ }^{\circ} \mathrm{C}$; ${ }^{1} \mathrm{H}-\mathrm{NMR}\left(\mathrm{CDCl}_{3}\right): \delta 7.90(\mathrm{~d}, \mathrm{~J}=7.9 \mathrm{~Hz}, 2 \mathrm{H}), 7.81(\mathrm{~d}, \mathrm{~J}=7.9 \mathrm{~Hz}, 2 \mathrm{H})$, 7.54-7.43 (m, 3H), 7.31 (d, J=7.9 Hz, 2H), 2.43 (s, 3H); MS m/z 196, (M+1, 88), 119 (100).

\section{References}


1. Thomson, R.H. Naturally Occurring Quinones IV; Blackie Academic \& Professional: London, 1997.

2. Spyroudis, S. Hydroxyquinones: Synthesis and Reactivity. Molecules 2000, 5, 1291-1330.

3. a) Hatzigrigoriou, E.; Spyroudis, S.; Varvoglis, A. Derivatives of 1,4-Naphthoquinone via 3(phenyliodonio)-1,2,4-trioxo-1,2,3,4-tetrahydronaphthalenide. Liebigs Ann. Chem. 1988, 167-170; b) Papoutsis, I.; Spyroudis, S.; Varvoglis, A. The Chemistry of 2-Oxido-3-phenyliodonio-1,4benzoquinones: Transformation to 2-Cyclopentene-1,4-diones and Cycloadditions. Tetrahedron Lett. 1994, 35, 8449-8452; c) Kobayashi, K.; Uneda, T.; Kawakita, M.; Morikawa, O.; Konishi, H. One-Pot Synthesis of Naphtho[2,3-b]furan-4,9-diones by Sequential Coupling/Ring Closure Reactions. Tetrahedron Lett. 1997, 38, 837-840; d) Stagliano, K.W.; Malinakova, H.C. Regiospecific Synthesis of Unsymmettrical 2,3-Diarylquinones via Stepwise $\operatorname{Pd}(0)$-Catalyzed Couplings of Arylstananes to Doubly Activated Quinone Equivalents. Tetrahedron Lett. 1997, 35, 6617-6620; e) Stagliano, K.W.; Malinakova, H.C. Regiospesific Synthesis of 2,3-Bisnaphthopyranyl Quinones related to Conocurvone. Effect of Substituents on Palladium-Catalyzed CrossCoupling of Organostannanes to Naphthopyranyl Hydroxyquinone Triflates. J. Org. Chem. 1999, 64, 8034-8040; f) Emadi, A.; Harwod, J.S.; Kohanim, S.; Stagliano, K.W. Regiocontroled Synthesis of the Trimeric Quinone Framework of Conocurvone. Org. Lett. 2002, 4, 521-524; g) Spyroudis, S.; Xanthopoulou, N. Triptycene Quinones in Synthesis: Preparation of Triptycene Cyclopentanedione and Its Reactivity as a Dienophile. J. Org. Chem. 2002, 67, 4612-4614; h) Spyroudis, S.; Xanthopoulou, N. Triptycene Quinones in Synthesis: Preparation of Triptycene Bis- cyclopentanedione. ARKIVOC. 2003, (vi), 95-105.

4. Malamidou-Xenikaki, E.; Spyroudis, S.; Tsanakopoulou, M. Studies on the Reactivity of 2Hydroxy-1,4-naphthoquinone: Reaction with Amines. J. Org. Chem. 2003, 68, 5627-5631.

5. Ma, D.; Zhang, Y.; Yao, J.; Wu, S.; Tao, F. Accelerating Effect Induced by the Structure of $\alpha-$ Amino Acid in the Copper-Catalyzed Coupling Reaction of Aryl Halides with $\alpha$-Amino Acids. Synthesis of Benzolactam-V8. J. Am. Chem. Soc. 1998, 120, 12459-12467.

6. Andrews, L.J. Aromatic Molecular Complexes of the Electron Donor-Aceptor Type. Chem. Rev. 1954, 54, 713-776.

7. a) Ley, S.V.; Thomas, A.W. Modern Synthetic Methods for Copper-Mediated C(aryl) -O,C(aryl)N, and C(aryl)-S Bond Formation. Angew. Chem. 2003, 42, 5400-5449; b) Job, G. E.; Buchwald, S.L. Copper-catalyzed Arylation of $\beta$-Amino Alcohols. Org. Lett. 2002, 4, 3703-3707; c) Lam, P.Y.S.; Bone, D.; Vincent, G.; Clark, C.G.; Combs, A.P. N-Arylation of $\alpha$ - aminoesters with $p$ tolylboronic acid promoted by copper (II) acetate. Tetrahedron Lett. 2003, 44, 1691-1694; d) Nandakumar, M.V. Copper catalyzed arylation of urea. Tetrahedron Lett. 2004, 45, 1989-1990.

8. Craig, G. The Nitro and Amino Derivatives of t-Butylbenzene J. Am. Chem. Soc. 1935, 57, 195198.

9. Tien, J.M.; Hunsberger, I.M. The Preparation of Substituted Hydrazines. III. A General Method for Preparing N-Substituted Glycines. J. Am. Chem. Soc. 1955, 77, 6696-6998.

10. Searles, S.; Gregory, V.P. The Reaction of Trimethyl Oxide with Amines. J. Am. Chem. Soc. 1954, 76, 2789-2890.

11. Burns, J.; McCombie, H.; Scarborough, H.B. Some Substitution Products of Azobenzene. J. Chem. Soc. 1928, 2929-2933. 
Sample availability: Not available.

(C) 2005 by MDPI (http://www.mdpi.org). Reproduction is permitted for noncommercial purposes. 